5. Колесов Е.В. Обоснование последовательного проветривания рабочих зон нескольких тупиковых выработок // Стратегия и процессы освоения георесурсов: сб. науч. тр. Вып. 16 / ГИ УрО РАН. Пермь, 2018. - C. 291-295. DOI: 10.7242/gdsp.2018.16.78

6. Tariq F., Bekir G. Evaluation of line brattice length in an empty heading to improve air flow rate at the face using CFD // International Journal of Mining Science and Technology. - 2017. - V. 27, № 2. - P. 253-259. DOI: $10.1016 /$ j.ijmst.2017.01.012

7. Torno S., Torano J., Ulecia M., Allende C. Conventional and numerical models of blasting gas behaviour in auxiliary ventilation of mining headings // Tunnelling and Underground Space Technology. - 2013. - V. 34. - P. 73-81. DOI: 10.1016/j.tust.2012.11.003

\title{
ИССЛЕДОВАНИЕ ГАЗОВОГО СОСТАВА РУДНИЧНОГО ВОЗДУХА ДЛЯ ОЦЕНКИ ВОЗМОЖНОСТИ ПРИМЕНЕНИЯ РЕЦИРКУЛЯЦИОННОГО ПРОВЕТРИВАНИЯ
}

\author{
Н.А. ТРУШКОВА \\ Горный институт УрО РАН, г. Пермь
}

\begin{abstract}
Аннотация: В работе представлены результаты исследований газового состава рудничного воздуха на калийных и медно-никелевых рудниках. В настоящее время рециркуляционное проветривание применяется только на калийных рудниках. На других рудниках, где применение рециркуляции не разрешено, все чаще возникает такая потребность, имеющая целью повышение качества проветривания рабочих зон и снижение количества потребляемой энергии. В данной работе проведен сравнительный анализ качества воздуха исходящей струи на калийных и медно-никелевых рудниках (Норильский никель), на основании которого сделана оценка возможности применения рециркуляционного проветривания.

Ключевые слова: схема проветривания, рудничный воздух, газовыделение, свежая струя, исходящая струя, рециркуляция, предельно-допустимая концентрация.
\end{abstract}

\section{Введение}

Рост производственных мощностей и развитие вентиляционных систем рудников приводит к тому, что зачастую главные вентиляторные установки и системы воздухоподготовки работают в режиме максимальной производительности для обеспечения рабочих зон требуемым количеством воздуха. Возникают участки, испытывающие дефицит воздуха, а увеличение подачи в рудник свежего воздуха невозможно по техническим характеристикам вентиляторов. Все чаще на рудниках возникает потребность в применении рециркуляции для повышения качества проветривания рабочих зон и снижения количества потребляемой энергии на проветривание и воздухоподготовку. Нормативными документами разрешено применение рециркуляции только на калийных рудниках, однако прямого запрета на использование рециркуляционных систем на других рудниках нет [1].

При применении рециркуляции часть отработанного воздуха за счет работы вспомогательного вентилятора подается на свежую струю и используется повторно. Безопасность и эффективность применения рециркуляции для повышения качества проветривания добычных участков и снижения энергозатрат на проветривание установлена на основании исследований газового состава рудничной атмосферы калийных рудников и динамики распространения газовых примесей, описанных в [2]. В настоящее время эффективность применения рециркуляции доказана на практике и системы частичного повторного использования воздуха широко применяются на калийных рудниках [3-9].

\section{Результаты исследований газового состава воздуха на руднике БКПРУ-4}

С целью определения газовой динамики на руднике БКПРУ-4 ПАО «Уралкалий» специалистами отдела Аэрологии и теплофизики ГИ УрО РАН выполнена серия измерений газового состава воздуха для оценки распространение метана и сероводорода в вентиляционной сети (газы, выделяющиеся при добыче). Измерения выполнялись на всех главных направлениях рудника в различные периоды года по маршруту от воздухоподающего ствола до вентиляционного через рабочие зоны, где происходит выделение вредностей (рис. 1).

По результатам измерений определена динамика распространения газовых примесей для всех направлений рудника, максимальные концентрации газов зафиксированы на Юговосточном направлении, результаты замеров приведены на рис. 2 для метана и сероводорода. 


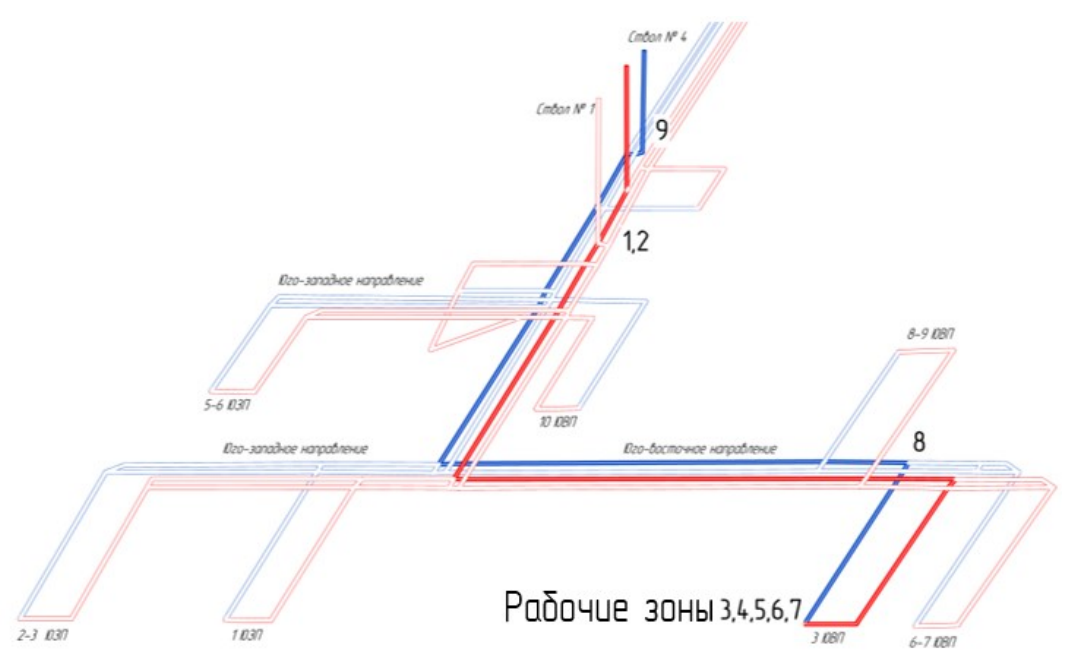

Рис. 1. Маршрут проведения замеров на Юго-восточном направлении

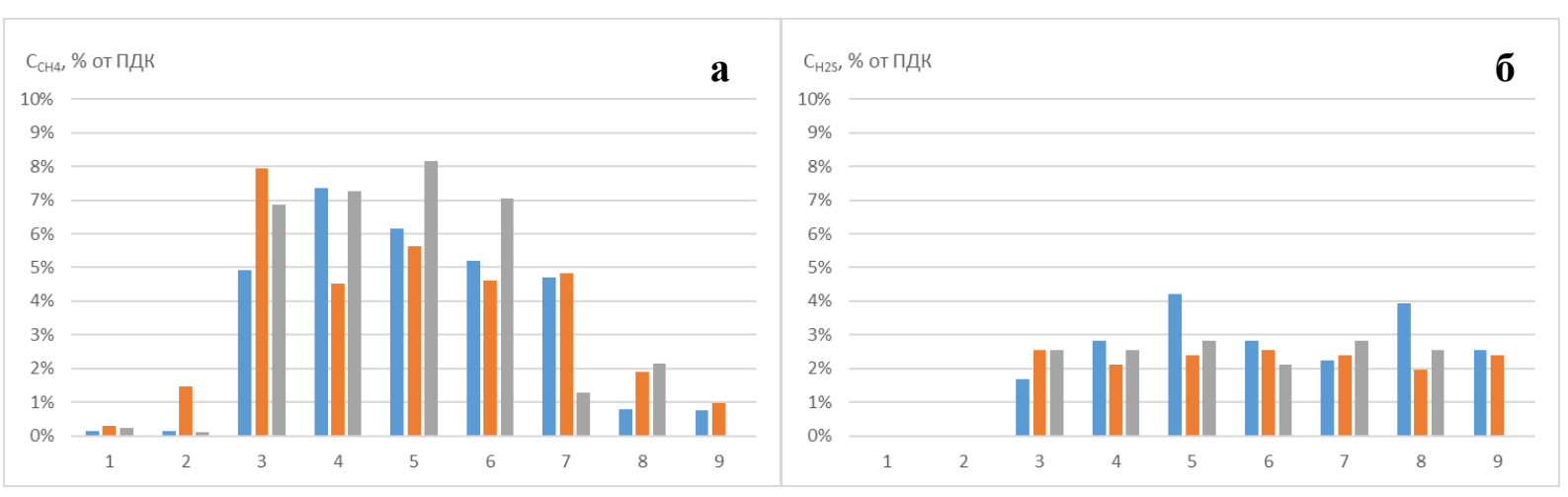

Рис. 2. Результат замеров концентрации метана (а) и сероводорода (б) на Юго-восточном направлении

Результат измерений показал, что максимальная концентрация газа в рабочей зоне не превышает $10 \%$ от ПДК для метана и $5 \%$ от ПДК для сероводорода. Далее наблюдается снижение концентрации газов по ходу движения отработанного воздуха в результате процессов сорбции и разбавления воздуха за счет утечек. Таким образом, подтверждаются ранее проведенные исследования газового состава рудничной атмосферы калийных рудников, отработанный воздух пригоден для использования.

Для вентиляционных систем калийных рудников характерны следующие параметры проветривания: центральная схема, всасывающий способ, коэффициент использования воздуха (т.е. отношение расчетного количества воздуха, необходимого для проветривания рудника, к фактически подаваемому) варьируется в диапазоне от 55 до 71 \%, концентрация газа на исходящей струе не превышает 10\% от ПДК. Медно-никелевые рудники проветриваются по фланговой схеме, при этом применяются всасывающий, нагнетательный или комбинированный способы проветривания, а коэффициент использования воздуха составляет 63-71\%. Анализ схем проветривания показал, что калийные и медно-никелевые рудники проветриваются по разным схемам разными способами проветривания, однако коэффициент использования воздуха варьируется в одинаковом диапазоне. Это послужило предпосылкой для рассмотрения рециркуляционного проветривания на медно-никелевых рудниках. Для этого в дальнейшем выполнены исследования качества отработанного воздуха для оценки возможности его повторного использования на медно-никелевых рудниках.

\section{Исследования газового состава воздуха на рудниках \\ ЗФ ПАО «ГМК «Норильский никель»}

Основными газами, выделяющимися при ведении горных работ на медно-никелевых рудниках, являются газы от взрывных работ и газовыделение от машин с двигателями внутреннего сгорания. Газы от взрывных работ в данном исследовании не рассматриваются, так как предполагается отключение рециркуляционных установок в момент 
проведения взрывных работ. Рассматриваемым источником выделения вредностей являются машины с двигателями внутреннего сгорания. При их работе выделяются ядовитые и токсичные газы, такие как оксид углерода и оксиды азота. Концентрация этих газов являлась основной измеряемой величиной, дополнительно выполнены измерения концентрации метана, углекислого газа, сероводорода, акролеина и формальдегида.

Измерения газового состава рудничного воздуха выполнены аналогично ранее проведенным замерам на руднике БКПРУ-4 по маршруту от воздухоподающего ствола до вентиляционного через рабочую зону с наибольшим количеством техники с двигателями внутреннего сгорания в одновременной работе. Замеры концентрации газов выполнены на семи рудниках ЗФ ПАО «ГМК «Норильский никель» (Таймырский, Октябрьский, Комсомольский, Скалистый, Маяк, Ангидрит и Известняков). На рис. 3 - 6 приведены маршруты и результаты проведения замеров концентрации газов на рудниках Ангидрит и Скалистый.

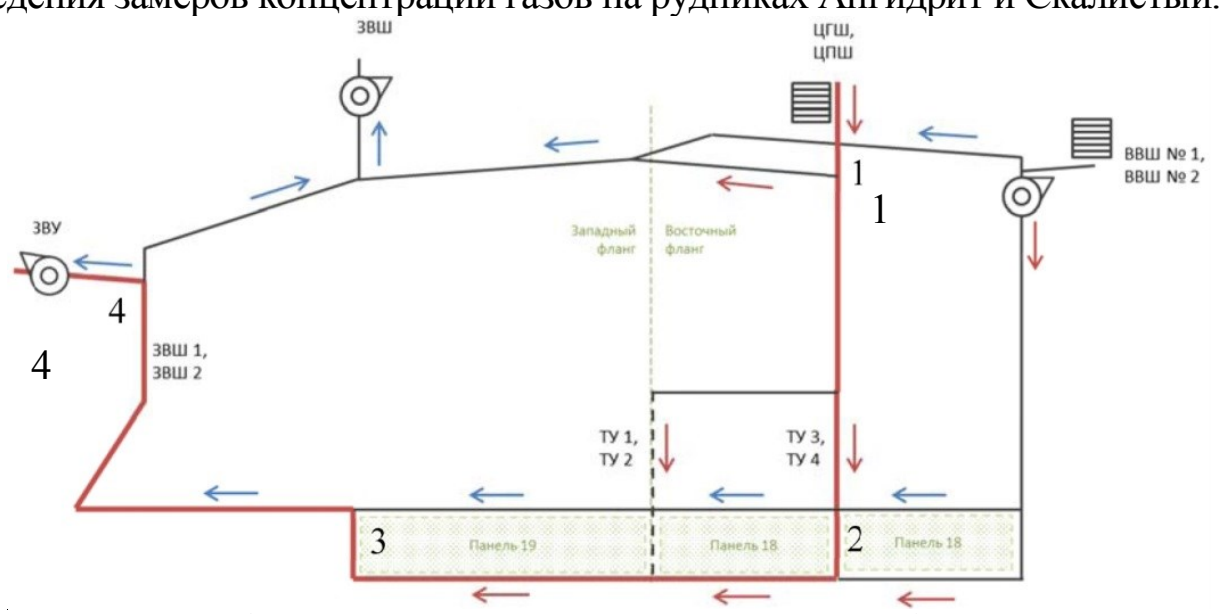

Рис. 3. Маршрут проведения замеров на руднике Ангидрит

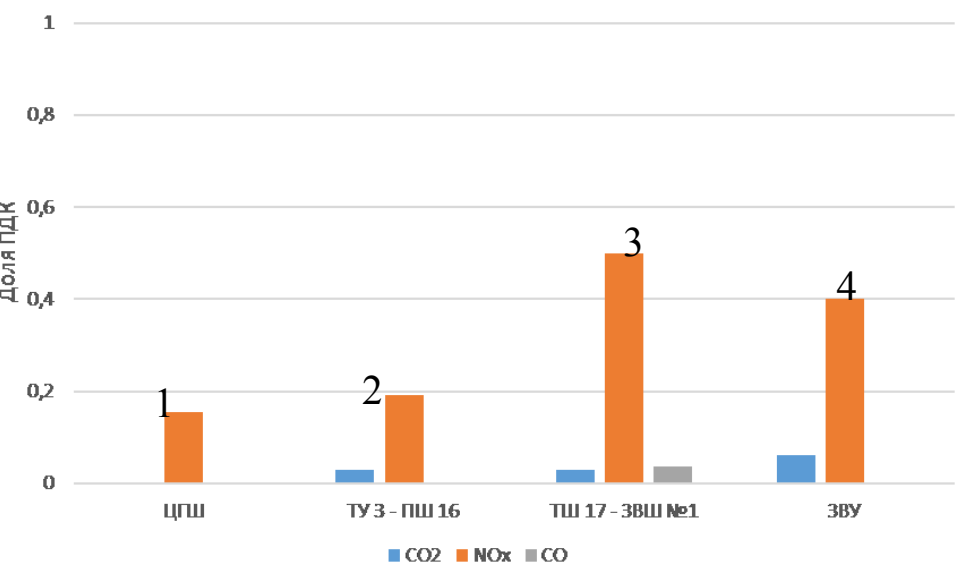

Рис. 4. Результат замеров газового состава воздуха на руднике Ангидрит

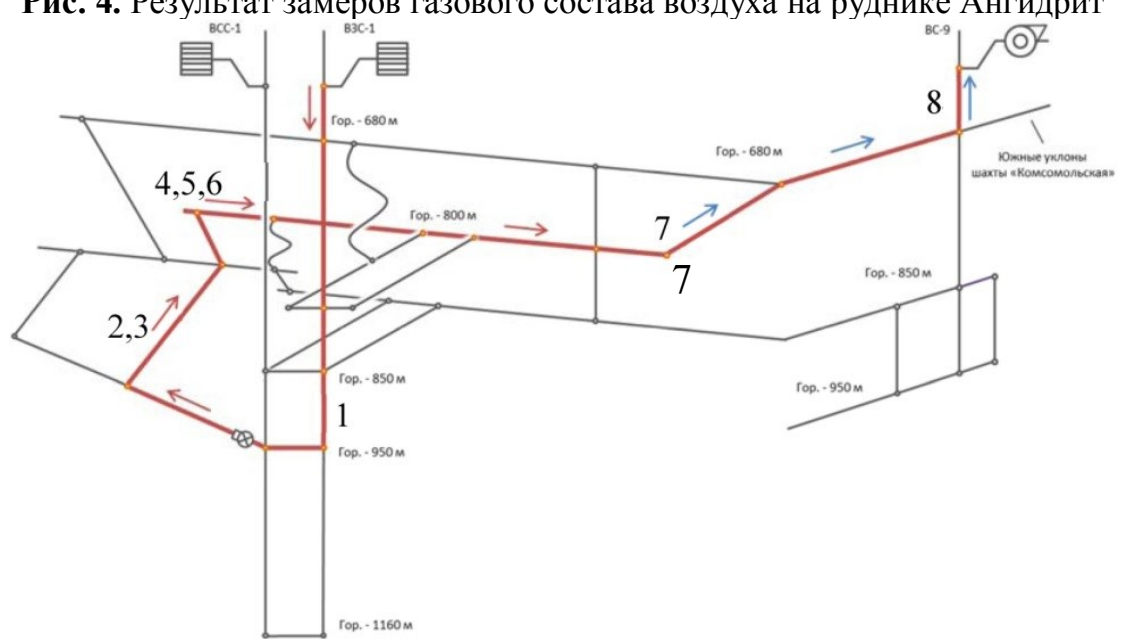

Рис. 5. Маршрут проведения замеров на руднике Скалистый 


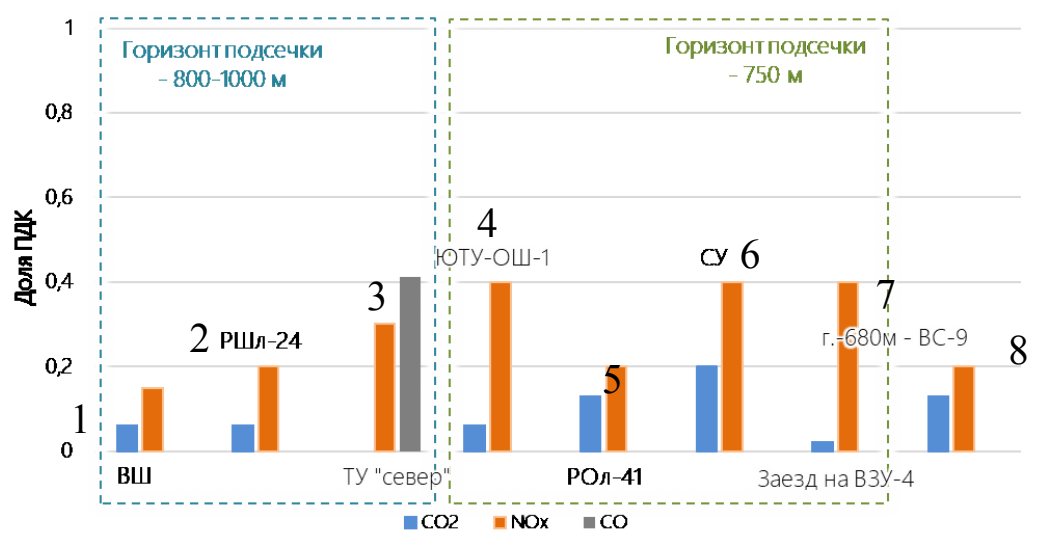

Рис. 6. Результат замеров газового состава воздуха на руднике Скалистый

Исследования показали, что наибольшая концентрация газа на исходящей струе не превышает $0,5 \%$ от ПДК. Сводные данные по газовому составу воздуха на исходящей струе по всем исследуемым рудникам приведены в табл. 1.

Таблица 1

Результат замеров газового состава воздуха

\begin{tabular}{|l|l|c|c|}
\hline Название & Формула & ПДК, \% об. & Доля ПДК \\
\hline Метан & $\mathrm{CH}_{4}$ & 0,5 & - \\
\hline Окись углерода & $\mathrm{CO}$ & 0,0017 & $0-0,4$ \\
\hline Углекислый газ & $\mathrm{CO}_{2}$ & 0,5 & $0-0,2$ \\
\hline Окислы азота (в пересчете ${\left.\mathrm{Ha} \mathrm{NO}_{2}\right)}$ ернистый газ & $\mathrm{NO}_{\mathrm{x}}$ & 0,00026 & $0-0,5$ \\
\hline Серн & $0-0,1$ \\
\hline Сероводород & $\mathrm{SO}_{2}$ & 0,00038 & - \\
\hline Акролеин & $\mathrm{H}_{2} \mathrm{~S}$ & 0,00071 & - \\
\hline Формальдегид & $\mathrm{C}_{3} \mathrm{H}_{4} \mathrm{O}$ & 0,000009 & - \\
\hline
\end{tabular}

Таким образом можно сделать вывод о том, что исходящая струя на рудниках ЗФ ПАО «ГМК «Норильский никель» пригодна для повторного использования. Для внедрения рециркуляционных систем на медно-никелевых рудниках требуется разработка методики требуемого количества воздуха с учетом рециркуляции и методика определения оптимального места размещения рециркуляционной установки.

\section{БИБЛИОГРАФИЧЕСКИЙ СПИСОК}

1. Федеральные нормы и правила в области промышленной безопасности «Правила безопасности при ведении горных работ и переработке твердых полезных ископаемых». Вып. 78: утв. 11.12.2013, № 32935. - М.: ЗАО НТЦ ПБ, 2019. - 302 с. - (Документы межотраслевого применения по вопросам промышленной безопасности и охраны недр: сер. 03). С изменениями от 21.11.2018.

2. Медведев И.И., Красноштейн А.Е. Аэрология калийных рудников / УрО АН СССР. - Свердловск, 1990. - 251 с.: ил.

3. Зайцев А.В., Клюкин Ю.А., Киряков А.С. Исследование процессов тепломассопереноса в горных выработках при применении систем частичного повторного использования воздуха // Вестн. ПНИПУ: Геология. Нефтегазовое и горное дело. - 2014. - Т. 13, № 11. - С.121-129.

4. Казаков Б.П., Левин Л.Ю., Шалимов А.В. Повышение эффективности ресурсосберегающих систем вентиляции для подземных рудников // Горн. журн. - 2014. - № 5. - С. 26-28.

5. Казаков Б.П., Шалимов А.В., Киряков А.С. К вопросу энергосбережения проветривания рудников // Физико-технические проблемы разработки полезных ископаемых. - 2013. - № 3. - С. 139-147.

6. Казаков Б.П., Трушкова Н.А., Зайцев А.В. Применение частичного повторного использования воздуха для снижения количества выпадающей влаги в калийных рудниках // Вестн. ПНИПУ: Геология. Нефтегазовое и горное дело. - 2012. - Т. 11, № 3. - С.129-133.

7. Казаков Б.П., Шалимов А.В., Исаевич А.Г. Проветривание калийных рудников с частичным повторным использованием // Изв. вузов. Горн. журн. - 2007. - № 4 . - С. 47-52.

8. Казаков Б.П., Левин Л.Ю. Исследование и разработка рециркуляционных систем проветривания рудников // Горн. журн. - 2006. - №12. - С. 71-73.

9. Трушкова Н.А., Казаков Б.П., Зайцев А.В., Гришин Е.Л. Применение рециркуляционных установок для повышения эффективности проветривания рудников с учетом обеспечения безопасных условий труда // Актуальные проблемы повышения эффективности и безопасности эксплуатации горношахтного и нефтепромыслового оборудования. - 2015. - Т. 1. - С. 283-290. 